\title{
ELECTROCHEMICAL KINETICS AND GROWTH MODES OF SILVER DEPOSITS ON POLYFACETED PLATINUM SPHERICAL ELECTRODES
}

\author{
A. Hernández Creus, P. Carro, S. González, R. C. Salvarezza* and A. J. Arvia* \\ Departamento de Química Física, Universidad de La Laguna, Tenerife, Spain
}

(Received 30 January 1992)

\begin{abstract}
The Ag electrodeposition on Pt spherical substrates was investigated over a wide range of experimental conditions to establish a correlation between the kinetics of the process and the different growth modes of the $\mathrm{Ag}$ overlayer. At $E_{\mathrm{d}} \cong E_{\text {rev }}$, the electrodeposition of the first $\mathrm{Ag}$ layer obeys a combined adsorption-desorption and nucleation and 2-D growth process under diffusion control. At $E_{\mathrm{d}}<E_{\mathrm{rev}}$, the formation of the 2-D Ag layer proceeds through an adsorption mechanism, whereas the formation of the 3-D Ag layer fits a progressive nucleation and 3-D growth mechanism under diffusion control. Finally, when $E_{d}<E_{\phi}$, a potential threshold related to $\mathrm{Ag}$ dendritic growth, the kinetics of the reaction apparently obeys a progressive nucleation and 1-D growth. This process is triggered at edges and corners of large Ag crystals. Dendritic growth takes place outside the diffusion layer defined around the Pt substrate sphere. In this case migration plays a substantial role in the process.
\end{abstract}

Key words: electrodeposition, Pt spherical substrates, migration.

\section{INTRODUCTION}

The growth of metal deposits has been studied rather extensively over the last few decades by using a number of electrochemical systems involving polycrystalline and single crystal substrates. A comprehensive survey of these contributions up to 1983 is given in Ref.[1].

Several stages can be distinguished during the metal electrodeposition, starting from the first monolayer[2-4] to the bulk metal. The bulk metal phase can be grown under different modes[5-7], covering from relatively smooth metal surfaces, sometimes implying well-defined crystallographic structures, to very rough metals such as those corresponding to either dendrites[8] or highly dispersed metal electrodes[9]. The growth mode of the proper metal electrodeposit and the development of a metal surface with specific characteristics, both being strongly dependent on the kinetics of the electrochemical reaction, are closely related[10-14]. In general, the metal deposition kinetics involves a number of variables which are associated with the characteristics of the substrate, the composition of the solution and the potential routine applied to the electrode[11].

The present work describes the texture changes taking place along the $\mathrm{Ag}$ electrodeposition on a $\mathrm{Pt}$ substrate under well-determined kinetic conditions. The transitions in the Ag growth mode as seen through scanning electron microscopy (SEM) imaging can be correlated to the changes in the $\mathbf{A g}$ electrodeposition kinetics resulting from electrochemical data. The different features of Ag electrodeposition described in this paper appear to be of

"Visiting Professor, INIFTA, CONICET, Argentina. general application to other metal electrocrystallization processes.

\section{EXPERIMENTAL}

All the runs were made in a conventional threeelectrode electrochemical cell under Ar atmosphere, at $25^{\circ} \mathrm{C}$. Polyfaceted spherical Pt substrates $(0.040$, 0.055 and $0.070 \mathrm{~cm}^{2}$ apparent area) were used as working electrodes. The electrodeposition of $\mathrm{Ag}$ was made from $5 \times 10^{-3} \mathrm{Ag}_{2} \mathrm{SO}_{4}+x \mathrm{M} \mathrm{H}_{2} \mathrm{SO}_{4}+y \mathrm{M}$ $\mathrm{Na}_{2} \mathrm{SO}_{4}\left(10^{-3}<x<10^{-2} ; 5 \times 10^{-2} \mathrm{M}<y<1.0 \mathrm{M}\right)$ at either a constant potential, $E_{\mathrm{d}}(-0.200 \mathrm{~V}<$ $\left.E_{\mathrm{d}}<E_{\mathrm{rev}}\right)$, or voltammetrically. In the present case the value of $E_{\text {rey }}$ was changed from $0.375 \mathrm{~V}$ (vs sce) to $0.400 \mathrm{~V}$, depending on the change of the $\mathrm{Ag}^{+}$ion activity with the concentration of the supporting electrolyte. The electrodeposition time, $t_{\mathrm{d}}$, was adjusted for obtaining different amounts of Ag electrodeposits. The counter electrode was a large Pt plate, and a saturated calomel electrode (sce) was employed as reference.

Current transients at $E_{\mathrm{d}}$ were recorded by applying the double potential step technique. Firstly the potential was stepped from 0.700 to $1.20 \mathrm{~V}$ to obtain a Ag-free Pt substrate, followed by a second potential step from $0.700 \mathrm{~V}$ to $E_{\mathrm{d}}$ to form the $\mathrm{Ag}$ deposit.

Conventional voltammetric runs related to the $\mathrm{Ag}$ electrodeposition $/ \mathrm{Ag}$ anodic stripping were made covering a wide range of experimental conditions. The electrochemical measurements were made by using a PAR circuitry including the 173,175 and 179 model units. Fast current transients were recorded with a model 3091 Nicolet oscilloscope. All solutions were prepared for a.r. chemicals and Milli $Q^{*}$ water. Runs were made under Ar which was purified in the 

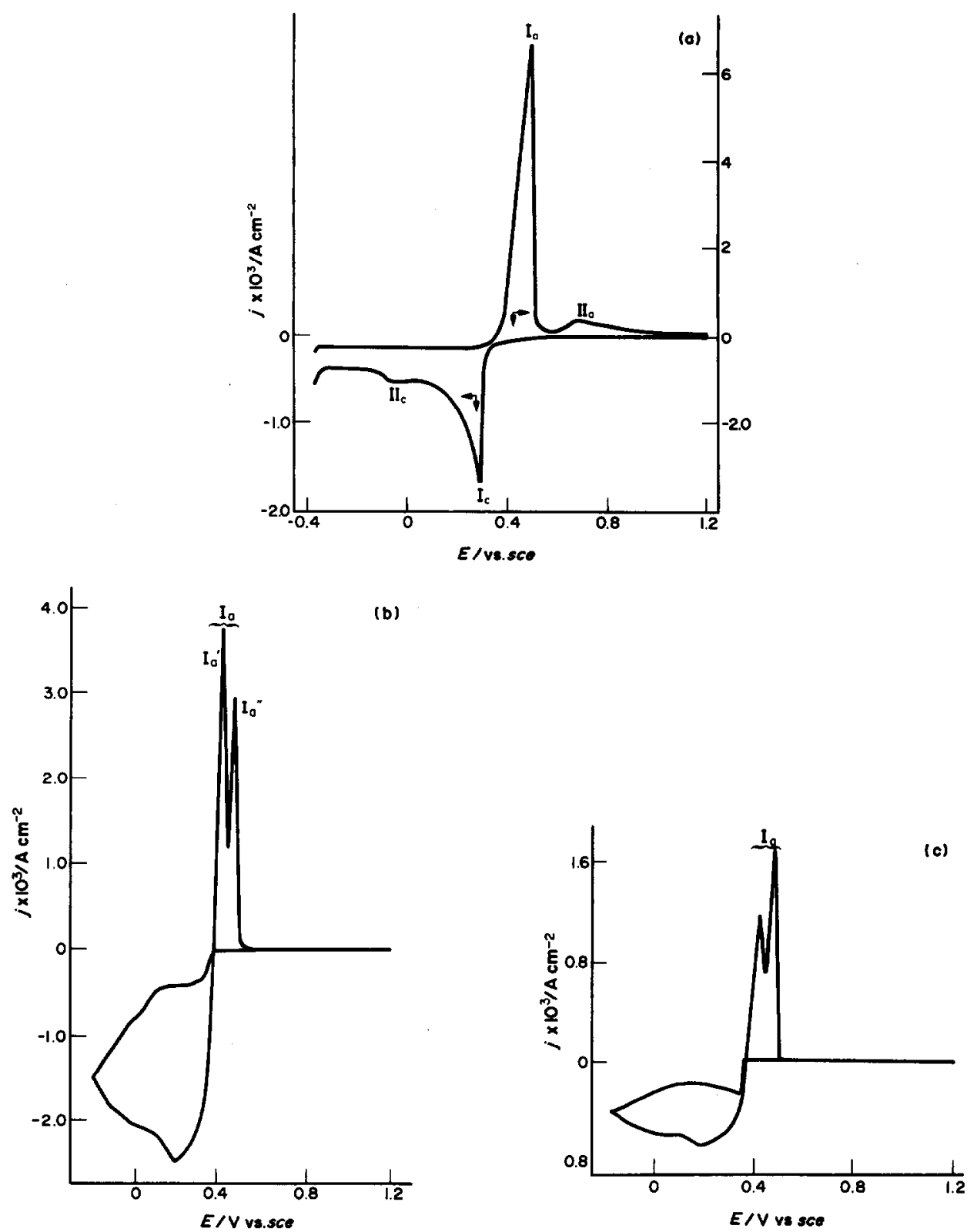

Fig. 1. Single sweep voltammograms corresponding to the electrodeposition and anodic stripping of $\mathrm{Ag}$ on Pt. (a) $0.5 \mathrm{M} \mathrm{Na} \mathrm{SO}_{4}+10^{-2} \mathrm{M} \mathrm{H}_{2} \mathrm{SO}_{4}+5 \times 10^{-3} \mathrm{M} \mathrm{Ag}_{2} \mathrm{SO}_{4}$ and $v=0.100 \mathrm{~V} \mathrm{~s}^{-1}$; (b) $0.5 \mathrm{M}$ $\mathrm{Na}_{2} \mathrm{SO}_{4}+10^{-2} \mathrm{M} \mathrm{H}_{2} \mathrm{SO}_{4}+5 \times 10^{-3} \mathrm{M} \mathrm{Ag}_{2} \mathrm{SO}_{4}$ and $v=0.001 \mathrm{~V}^{-1}$; (c) $1.0 \mathrm{M} \mathrm{Na} \mathrm{SO}_{4}+10^{-2} \mathrm{M}$ $\mathrm{H}_{2} \mathrm{SO}_{4}+5 \times 10^{-3} \mathrm{M} \mathrm{Ag}_{2} \mathrm{SO}_{4}$ and $v=0.001 \mathrm{~V} \mathrm{~s}^{-1}$.

usual way to eliminate traces of $\mathrm{O}_{2}$ and organic impurities.

SEM micrographs of Ag electrodeposits were systematically obtained with a Hitachi S-450 scanning electron microscope.

\section{RESULTS}

\subsection{Voltammetry data}

3.1.1. Voltammetric Ag electrodeposition. The electrodeposition/anodic stripping voltammograms depend considerably on the amount of electrodeposited $\mathrm{Ag}$, on $v$, the potential sweep rate, and on $E_{\mathrm{sc}}$, the cathodic switching potential. The following description is based on two limiting situations, namely runs made at $0.1 \mathrm{~V} \mathrm{~s}^{-1}$ involving relatively small $\mathbf{A g}$ electrodeposition charges and runs made at $0.001 \mathrm{~V}$ $\mathrm{s}^{-1}$ comprising the opposite situation.

At $v=0.1 \mathrm{~V} \mathrm{~s}^{-1}$ (Fig. la) the first negative potential-going scan starting from $1.20 \mathrm{~V}>E_{\mathrm{rev}}$ exhibits a cathodic current peak (Ic) at $0.270 \mathrm{~V}$ implying a fast current increase up to a peak value and a relatively slow current decay extending to $-0.390 \mathrm{~V}$ with a broad peak IIc superimposed at $-0.100 \mathrm{~V}$. As the potential scan reaches $-0.400 \mathrm{~V}$, the initiation of the HER current can be observed. The returning potential scan consists of a smoothly decaying cathodic 
Table 1. Cathodic limiting current related to $\mathrm{Ag}^{+}$ion discharge obtained from the voltammograms run at $0.001 \mathrm{~V} \mathrm{~s}^{-1}$

\begin{tabular}{lc}
\hline Electrolyte & $\begin{array}{c}j_{\text {lim }} / \\
\mathrm{mA} \mathrm{cm}-2\end{array}$ \\
\hline $0.05 \mathrm{M} \mathrm{Na}_{2} \mathrm{SO}_{4}+10^{-3} \mathrm{M} \mathrm{H}_{2} \mathrm{SO}_{4}+5 \times 10^{-3} \mathrm{M} \mathrm{Ag}_{2} \mathrm{SO}_{4}$ & 0.420 \\
$0.5 \mathrm{M} \mathrm{Na}_{2} \mathrm{SO}_{4}+10^{-2} \mathrm{M} \mathrm{H}_{2} \mathrm{SO}_{4}+5 \times 10^{-3} \mathrm{M} \mathrm{Ag}_{2} \mathrm{SO}_{4}$ & 0.400 \\
$1.0 \mathrm{M} \mathrm{Na}_{2} \mathrm{SO}_{4}+10^{-2} \mathrm{M} \mathrm{H}_{2} \mathrm{SO}_{4}+5 \times 10^{-3} \mathrm{M} \mathrm{Ag}_{2} \mathrm{SO}_{4}$ & 0.180 \\
\hline
\end{tabular}

current (pseudo-plateau) covering from -0.350 to about $0.270 \mathrm{~V}$. The overall cathodization apparent

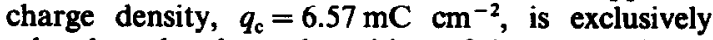
related to the electrodeposition of $\mathrm{Ag}$ on $\mathrm{Pt}$. As $E_{\mathrm{d}}$ exceeds $E_{\text {rev }}$, a large $\mathrm{Ag}$ anodic stripping peak (Ia) at $0.500 \mathrm{~V}$ followed by a rather symmetric broad peak (IIa) at $0.685 \mathrm{~V}$ can be observed. The total anodic charge related to peak IIa is $0.642 \mathrm{mC} \mathrm{cm}^{-2}$, a figure exceeding the $\mathrm{Ag}$ upd monolayer charge density $\left(0.36 \mathrm{mC} \mathrm{cm} \mathrm{cm}^{-2}\right)$. The difference in the anodic stripping charge density involves a certain amount of $\mathrm{Ag}$ from $\mathrm{Ag}-\mathrm{Pt}$ surface alloy[12-14] and O-electroadsorption on bare $\mathrm{Pt}[14,15]$.

The voltammogram run at $0.001 \mathrm{~V} \mathrm{~s}^{-1}$ (Fig. 1b) shows drastic changes compared with the voltammogram already described, particularly at $E_{\mathrm{d}}<E_{\mathrm{rev}}$. The overall $\mathrm{Ag}$ electrodeposited charge density is about $1650 \mathrm{mC} \mathrm{cm}^{-2}$. The corresponding negative potential-going scan attains firstly a current pseudoplateau ( $c a 0.40 \mathrm{~mA} \mathrm{~cm} \mathrm{~cm}^{-2}$ ) ranging from 0.260 to $0.130 \mathrm{~V}$ with a small inflexion. From a certain threshold potential $E_{\phi}=0.130 \mathrm{~V}$ downwards to $E_{\mathrm{sc}}$ a linear increase of current with the applied potential is displayed. During the Ag layer growth the area of the electrodeposit suddenly begins to increase at $E_{\phi}$, just when the formation of a visible rough $\mathrm{Ag}$ deposit begins. During the reverse scan there is a remarkable hysteresis in the cathodic current, although the same linear current-potential behaviour is kept until the potential becomes more positive than $E_{\phi}$. In the $0.090-0.290 \mathrm{~V}$ range a broad and complex cathodic peak is recorded. Afterwards, the current changes from cathodic to anodic at $E_{\mathrm{rev}}$ and immediately a complex Ag anodic stripping peak Ia is observed. The latter splits into peaks $I^{\prime} a$ and $I^{\prime \prime} a$, the corresponding peak potentials being 0.420 and $0.470 \mathrm{~V}$, respectively. In this case, the charge of peak IIa remains the same independent of $v$, although it can no longer be observed in the scale used in Fig. 1b.

The influence of the resistance of the electrolyte solution on the cathodic pseudo-limiting current was tested by changing the $\mathrm{Na}_{2} \mathrm{SO}_{4}$ concentration from $5 \times 10^{-2}$ to $1.0 \mathrm{M}$ (Fig. 1a-c). Data from the voltammograms run at $0.001 \mathrm{~V} \mathrm{~s}^{-1}$ are assembled in Table 1 . Accordingly, as the ionic strength of the solution is increased, $j_{\mathrm{lim}}$, the cathodic pseudo-limiting current decreases, $E_{\phi}$ shifts negatively, the charge involved in the hysteresis loop decreases and the formation of the rough Ag deposit can hardly be observed. Hence, the increase of the ionic strength of the solution hinders to some extent the type of $\mathrm{Ag}$ growth process triggered at $E_{\phi}$, which leads to a large increase in the area of the Ag deposit. These facts show that both the ion migration and the electric field in the solution play a significant role in the $\mathrm{Ag}$ electrodeposition when $E<E_{\phi}[16]$.
Runs made in $0.5 \mathrm{M} \mathrm{Na}_{2} \mathrm{SO}_{4}+10^{-2} \mathrm{M} \mathrm{H}_{2} \mathrm{SO}_{4}$ by changing $v$ and the electrolyte composition show a clear transition in the voltammograms which can be summarized as follows.

(i) Peak Ic tends to disappear and to be replaced by a cathodic current pseudo-plateau which extends from 0.260 to $0.130 \mathrm{~V}$ at $0.001 \mathrm{~V} \mathrm{~s}^{-1}$.

(ii) Following the cathodic pseudo-limiting current, the extent of the linear portion of the voltammogram increases and it includes an inflexion which corresponds to the contribution of peak IIc.

(iii) The hysteresis loop involving the cathodic charge becomes better defined. At high $v$ s the returning scan lies below the initial negative potential-going scan, whereas the opposite effect is noticed for $v$ $<0.020 \mathrm{~V} \mathrm{~s}^{-1}$.

(iv) Peak Ia shows always a hump at its negative branch which is better defined as the $\mathrm{Ag}$ electrodeposition charge increases.

(v) As $v$ increases the charge balance derived from the voltammograms expressed as the anodic $\left(Q_{\mathrm{a}}\right)$ to the cathodic $\left(Q_{c}\right)$ charge ratio, approaches unity (Fig. 2a). For a single cyclovoltammogram made between $1.20 \mathrm{~V}$ and $E_{s c}$, the $Q_{\mathrm{a}} / Q_{\mathrm{c}}$ ratio $v s v$ plot implies two apparent linear portions with a crossing at $v \cong 0.015 \mathrm{~V} \mathrm{~s}^{-1}$, corresponding to two drastically different rates of decrease of the $Q, Q_{c}$ ratio with $v$.

(vi) For $v>0.010 \mathrm{~V} \mathrm{~s}^{-1}$, the height of peak Ic increases linearly with $v^{1 / 2}$ (Fig. 2b), as one should expect for an electrochemical reaction which is kinetically controlled by the diffusion of the reactant from the solution.

(vii) The decay of peak Ic does not fit a simple current $v s t^{-1 / 2}$ relationship. In contrast, the cathodic pseudo-limiting current recorded during the returning potential scan from $E_{\mathrm{sc}}$ downwards becomes practically independent of $v$ for $v>0.010 \mathrm{~V} \mathrm{~s}^{-1}$, as expected for a diffusion controlled reaction at the spherical diffusion field[17]. This contribution is about $0.30 \mathrm{~mA} \mathrm{~cm}^{-2}$.

(viii) The cathodic charge involved in the initial cathodic current pseudo-plateau $\left(Q_{\mathrm{di}}\right)$ fits a linear dependence with the reciprocal of $v$ (Fig. $2 \mathrm{c}$ ), ie the product $Q_{\mathrm{di}} v$ appears to be a constant.

(ix) For a constant ionic composition, the slope of the linear current-potential region in the voltammograms depends on $v$ (Fig. 2d).

3.1.2. Anodic stripping voltammetry. The influence of $\mathrm{E}_{s c}, \mathrm{v}$ and electrodeposition time. To investigate the appearance of peaks Ia, I'a and $I^{\prime \prime} a$, a series of voltammograms was run by changing $E_{x c}$ stepwise from 0.100 to $-0.400 \mathrm{~V}$.

At $v=0.001 \mathrm{~V} \mathrm{~s}^{-1}$ and $E_{x c}=0.100 \mathrm{~V}$ (Fig. 3a), peak Ia appears at $0.470 \mathrm{~V}$, it exhibits a small hump at the ascending branch, and decays rather abruptly. In this case, the $Q_{\mathrm{a}} / Q_{\mathrm{c}}$ ratio is equal to 0.43 . This 
(a)
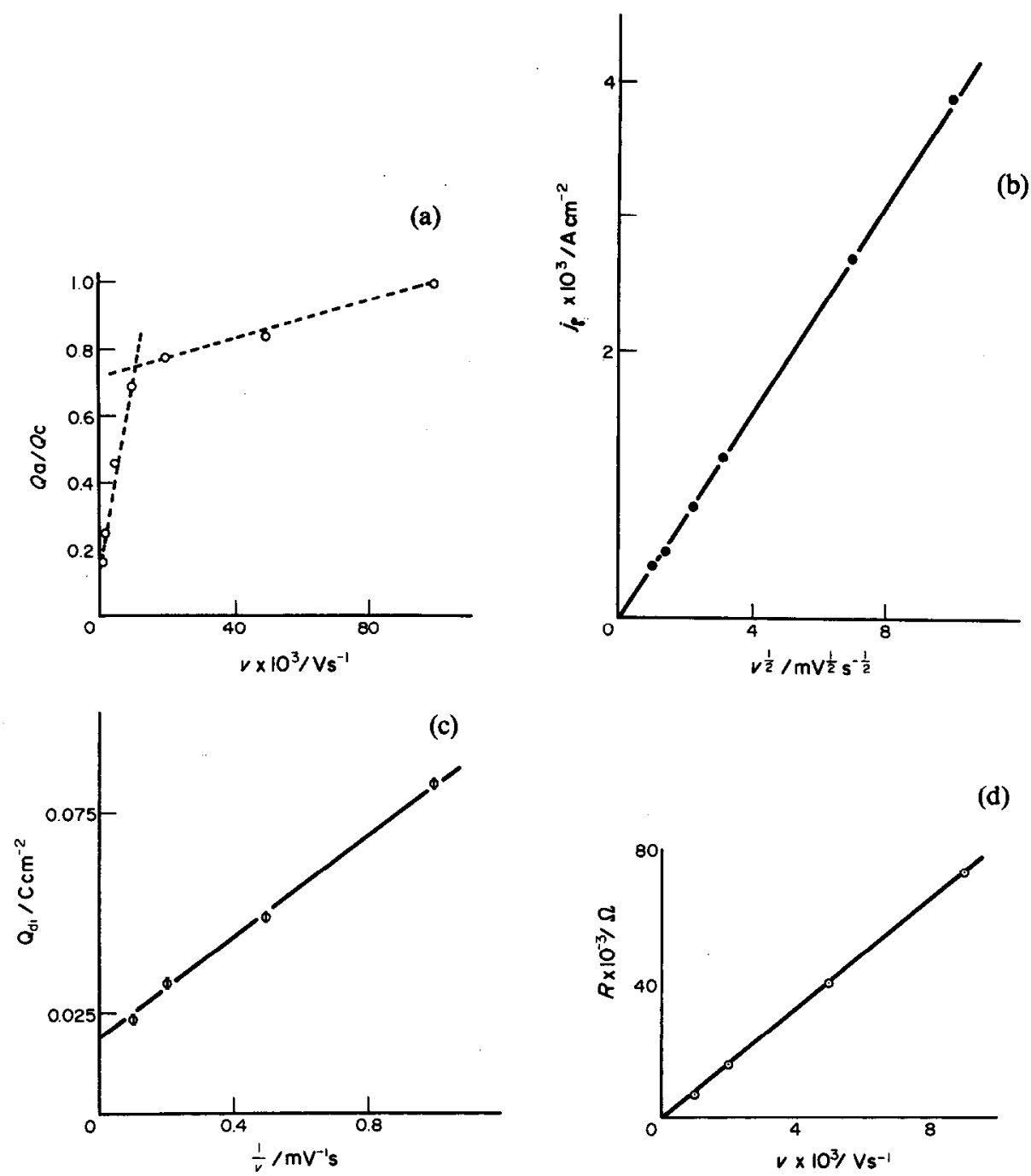

(d)

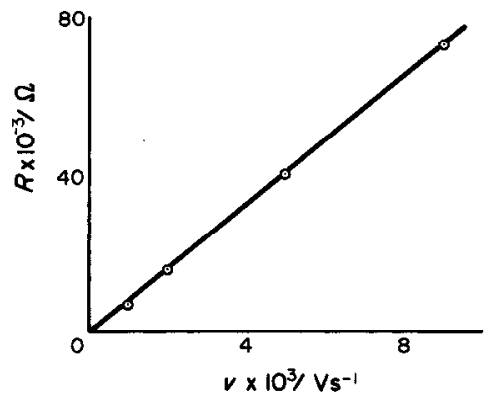

Fig. 2. (a) Plot of the anodic to cathodic charge ratio derived from voltammetry $v s$ the potential sweep rate. $0.5 \mathrm{M} \mathrm{Na}_{2} \mathrm{SO}_{4}+10^{-2} \mathrm{M} \mathrm{H}_{2} \mathrm{SO}_{4}+5 \times 10^{-3} \mathrm{M} \mathrm{Ag}_{2} \mathrm{SO}_{4}$. (b) Dependence of the voltammetric cathodic peak height on the square root of the potential sweep rate. $0.5 \mathrm{M} \mathrm{Na}_{2} \mathrm{SO}_{4}+10^{-2} \mathrm{M} \mathrm{H}_{2} \mathrm{SO}_{4}+5 \times 10^{-3} \mathrm{M}$ $\mathrm{Ag}_{2} \mathrm{SO}_{4}$. (c) Plot of the cathodic charge involved in the voltammetric plateau vs the reciprocal of the potential sweep rate. $0.5 \mathrm{M} \mathrm{Na}_{2} \mathrm{SO}_{4}+10^{-2} \mathrm{M} \mathrm{H}_{2} \mathrm{SO}_{4}+5 \times 10^{-3} \mathrm{M} \mathrm{Ag}_{2} \mathrm{SO}_{4}$. (d) Plot of the linear slope resulting from the voltammograms for $E>E_{\phi}$ us the potential sweep rate. $0.5 \mathrm{M} \mathrm{Na}_{2} \mathrm{SO}_{4}+10^{-2} \mathrm{M}$ $\mathrm{H}_{2} \mathrm{SO}_{4}+5 \times 10^{-3} \mathrm{M} \mathrm{Ag}_{2} \mathrm{SO}_{4}$.

figure reveals that a fraction of the Ag electrodeposit does not appear through the anodic stripping charge. Otherwise, when $E_{\mathrm{sc}}=-0.050 \mathrm{~V}<E_{\phi}$ (Fig. 3b), peaks I'a and I"a are observed, and the $Q_{\mathrm{a}} / Q_{\mathrm{c}}$ ratio is equal to 0.22 . The loss of $\mathrm{Ag}$ increases with the amount of $\mathrm{Ag}$ electrodeposit.

The same run made at $v=0.050 \mathrm{~V} \mathrm{~s}^{-1}$ shows that for all $E_{\mathrm{ac}}$, peak Ia appears as a single peak similar to that displayed in Fig. 1a, although the contribution of the hump at the ascending branch of peak Ia increases as $E_{s c}$ is shifted negatively. In these experiments the $Q_{\mathrm{a}} / Q_{\mathrm{c}}$ ratio becomes close to unity for $-0.320 \mathrm{~V}<E_{\mathrm{sc}}<0.60 \mathrm{~V}$.

Voltammograms were run at either $v=0.005 \mathrm{~V} \mathrm{~s}^{-1}$ or $v=0.050 \mathrm{~V} \mathrm{~s}^{-1}$, by setting $E_{\mathrm{sc}}$ in the $0.180 \mathrm{~V}>$ $E_{x c}>-0.310 \mathrm{~V}$ range, including occasionally a potential holding at $E_{x c}$ to accumulate an amount of Ag equal to that resulting at the same $v$ for
$E_{\mathrm{sc}}=-0.400 \mathrm{~V}$. In all cases, the $Q_{\mathrm{a}} / Q_{\mathrm{c}}$ ratio is greater than 0.90 , and peak Ic appears as a single peak. These results allow to conclude that the behaviour of the anodic stripping voltammograms is mainly determined by the value of $E_{\mathrm{sc}}$ instead of the Ag electrodeposition time.

The partial detachment of the $\mathbf{A g}$ electrodeposit decreases the amount of $\mathrm{Ag}$ anodically stripped off. This fact can be related to the type of growth mode of $\mathrm{Ag}$ at different potentials, as discussed further on.

\subsection{Potentiostatic current transients}

To understand the processes related to the $\mathrm{Ag}$ layer growth potentiostatic current transients were run in the $-0.200 \mathrm{~V}<E_{\mathrm{d}}<0.370 \mathrm{~V}$ range, and were recorded in the minute and second time scales (Fig. 4a and b). 

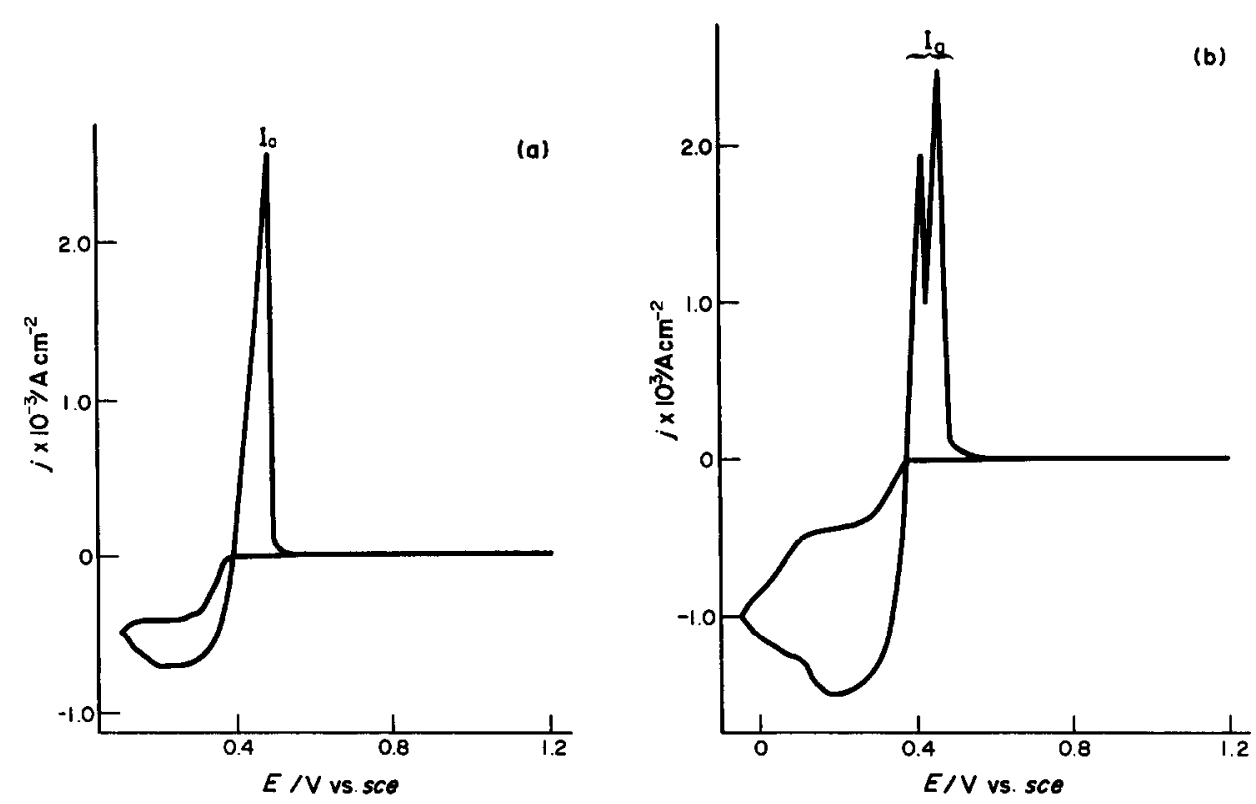

Fig. 3. Influence of $E_{\mathrm{sc}}$ on the single sweep voltammograms for the $\mathrm{Ag}$ electrodeposition and anodic stripping. (a) $E_{\mathrm{sc}}=0.100 \mathrm{~V}$; (b) $E_{\mathrm{sc}}=-0.050 \mathrm{~V} ; 0.5 \mathrm{M} \mathrm{Na}_{2} \mathrm{SO}_{4}+10^{-2} \mathrm{M} \mathrm{H}_{2} \mathrm{SO}_{4}+5 \times 10^{-3} \mathrm{M} \mathrm{Ag}_{2} \mathrm{SO}_{4}$. $v=0.001 \mathrm{~V} \mathrm{~s}^{-1}$.

When $E_{\mathrm{d}} \geq 0.370 \mathrm{~V}$, a potential very close to $E_{\text {rev }}$, the cathodic current decays exponentially to reach a value equal to $2.85 \mu \mathrm{A} \mathrm{cm} \mathrm{cm}^{-2}$. Otherwise, when $0.34 \mathrm{~V} \geq E_{\mathrm{d}} \geq 0.30 \mathrm{~V}$, the current decays first to a minimum value, and afterwards increases slowly with time. In the $0.300 \mathrm{~V} \geq E_{\mathrm{d}} \geq 0.150 \mathrm{~V}$ range, the current vs $t$ plot also firstly decays to a minimum value, but then increases to a maximum current, $I_{\mathrm{M}}$, at time $t_{\mathrm{M}}$,

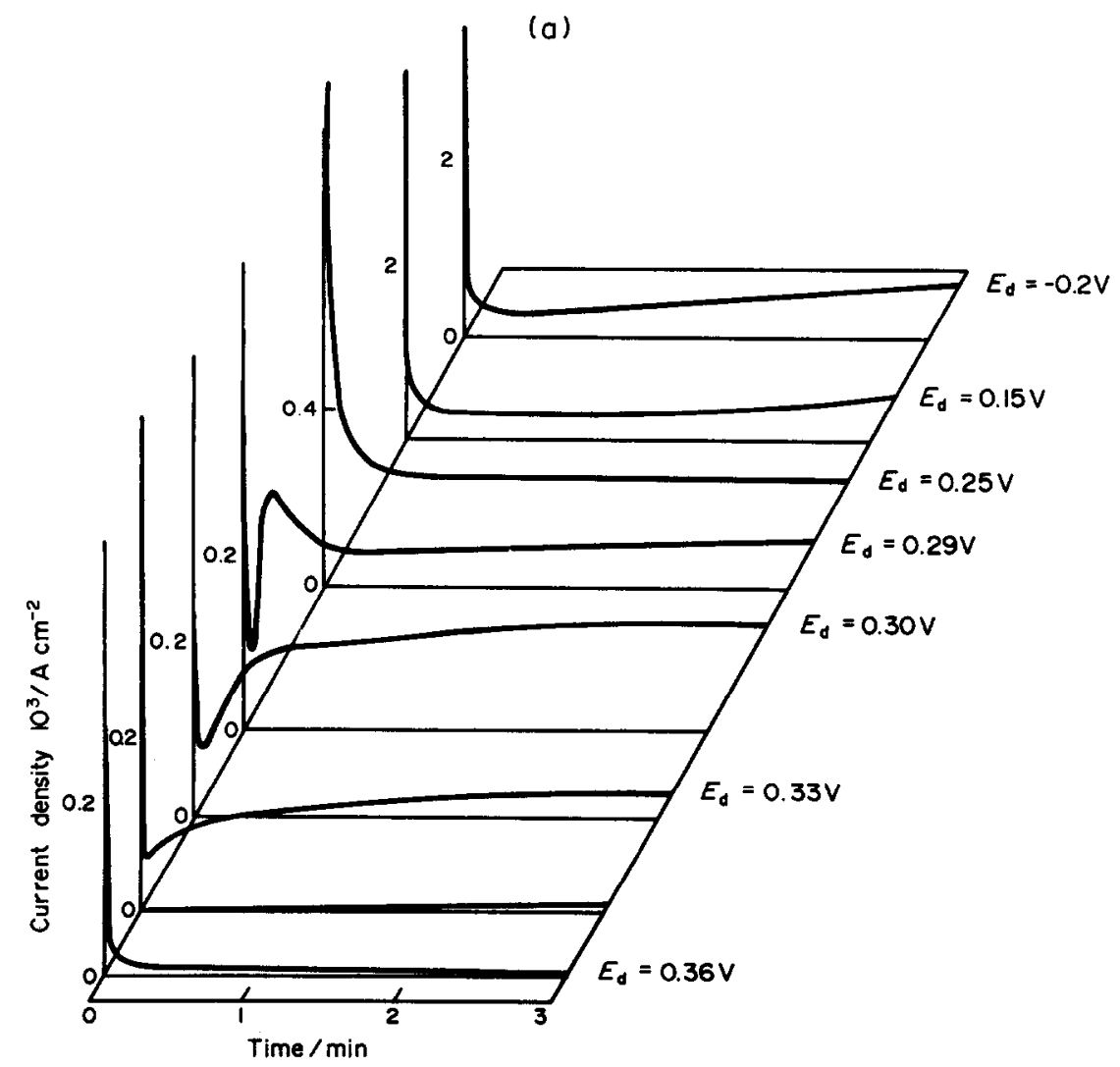

Fig. 4(a) (continued overleaf) 


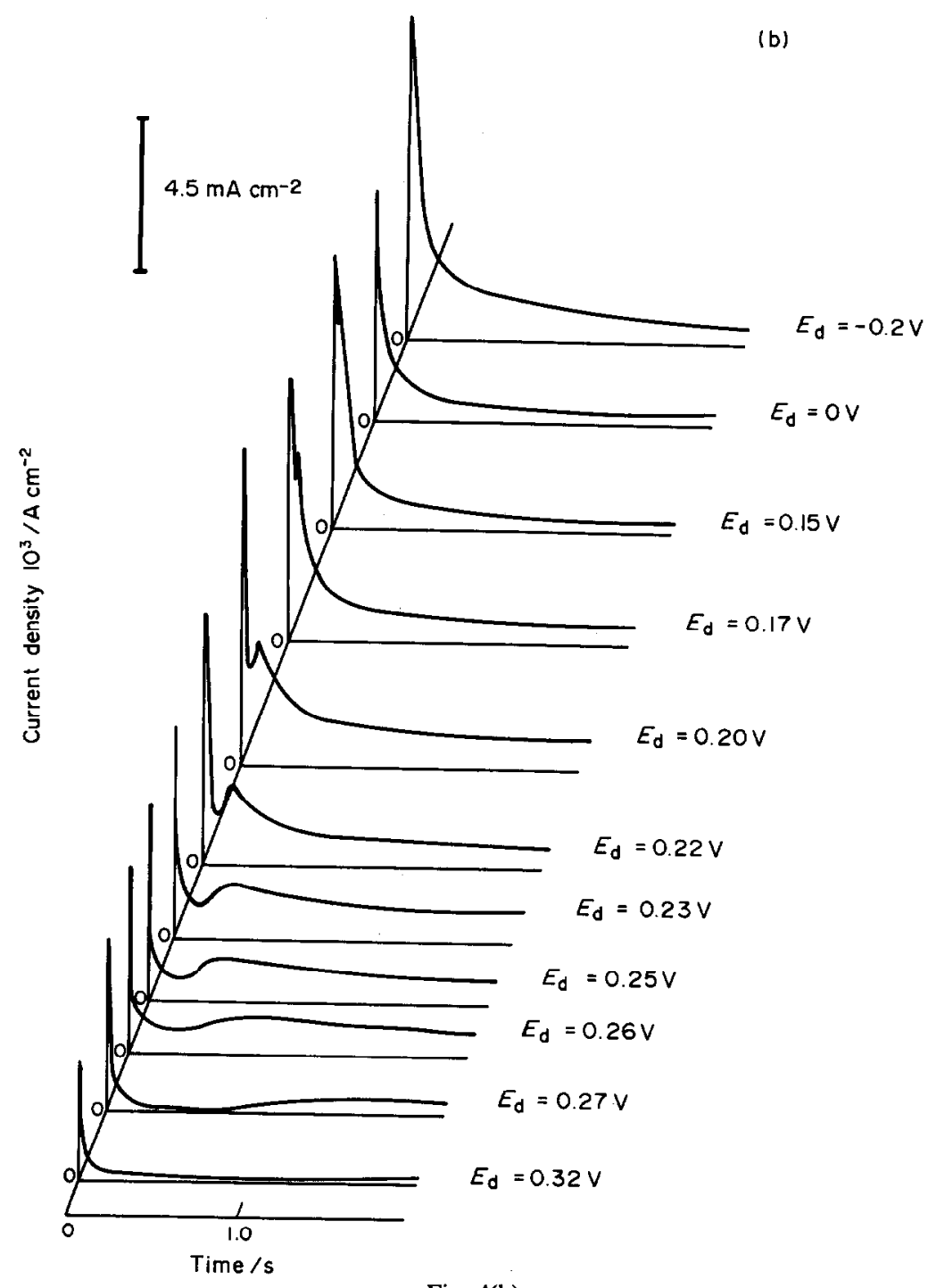

Fig. 4(b)

Fig. 4. Potentiostatic current transients (a) and (b) run at two time windows. $0.5 \mathrm{M} \mathrm{Na}_{2} \mathrm{SO}_{4}+10^{-2} \mathrm{M}$ $\mathrm{H}_{2} \mathrm{SO}_{4}+5 \times 10^{-3} \mathrm{M} \mathrm{Ag}_{2} \mathrm{SO}_{4}$.

later it decreases, and finally approaches a limiting current. In this case, as $E_{\mathrm{d}}$ is set more negative, $I_{\mathrm{M}}$ increases and $t_{\mathrm{M}}$ decreases.

For $E_{\mathrm{d}}<0.150 \mathrm{~V}$ current transients go through a broad minimum, and subsequently begin to increase linearly with time. The slope of these lines increases slightly with $E_{\mathrm{d}}$ and also depends on the solution composition, but it reaches a limiting value for $5 \times 10^{-2} \mathrm{M} \mathrm{Na}_{2} \mathrm{SO}_{4}+10^{-3} \mathrm{M} \mathrm{H}_{2} \mathrm{SO}_{4}$. The value of the slope derived from the $j$ vs $t$ plot coincides with that derived from the voltammogram at $0.001 \mathrm{~V} \mathrm{~s}^{-1}$ (Fig. 5).

The analysis of the potentiostatic current transients shows that different processes with distinguishable time constants are involved in the electrodeposition of Ag. Accordingly, for $E_{\mathrm{d}}<E_{\text {rev }}$ the current transient can be adjusted by using different $j=j(t)$ functions.

\subsection{SEM micrographs}

The SEM micrographs of $\mathrm{Ag}$ deposits resulting for $7 \mathrm{mC} \mathrm{cm} \mathrm{cm}^{-2}<Q_{\mathrm{d}}<80 \mathrm{mC} \mathrm{cm}^{-2}$ and $0.300 \mathrm{~V}<E_{\mathrm{d}}<$ $0.320 \mathrm{~V}$ ranges (Fig. $6 \mathrm{a}$ and $\mathrm{b}$ ) show the $\mathrm{Pt}$ substrate covered by a number of 3-D small crystals with diameters ranging between 0.3 and $3.0 \mu \mathrm{m}$, the average density being $10^{7} \mathrm{~cm}^{-2}$, a certain number of these crystals exhibiting simple geometric forms. For the largest values of $Q_{\mathrm{d}}$ the average size of $\mathrm{Ag}$ crystals increases and occasionally the overlapping of growing crystals can be observed. A small number of large and flat crystals with a hexagonal-like geometry randomly oriented on the substrate are also seen (Fig. 6b). Besides, the small 3-D crystals lying around the large crystals present rather diffuse etching-like patterns. This fact suggests that the formation of large crystals proceeds through a recrystallization process. 


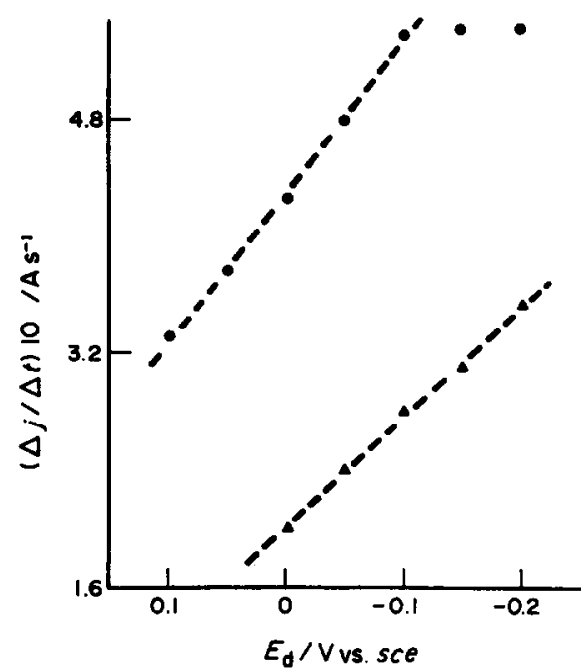

Fig. 5. Slope of the linear portion obtained from the potentiostatic current transient depicted in Fig. 8, for $E_{\mathrm{d}}<E_{\phi}$, us the electrodeposition potential. $0.5 \mathrm{M}$ $\mathrm{Na}_{2} \mathrm{SO}_{4}+10^{-2} \mathrm{M} \mathrm{H}_{2} \mathrm{SO}_{4}+5 \times 10^{-3} \mathrm{M} \mathrm{Ag}_{2} \mathrm{SO}_{4}(\triangle) ; 0.5 \mathrm{M}$ $\mathrm{Na}_{2} \mathrm{SO}_{4}+10^{-3} \mathrm{M} \mathrm{H}_{2} \mathrm{SO}_{4}+5 \times 10^{-3} \mathrm{M} \mathrm{Ag}_{2} \mathrm{SO}_{4}(\mathrm{O})$.

The SEM micrographs of $\mathrm{Ag}$ deposits produced at $E_{\mathrm{d}}=-0.200 \mathrm{~V}$, ie $E_{\mathrm{d}}<E_{\phi}$, exhibit typical dendritic patterns (Fig. 6e) leading to "metal forest" displays. The SEM micrographs also show the formation of a number of 3-D small Ag nuclei (Fig. 6f).

The transition between 3-D Ag crystals and $\mathbf{A g}$ dendrites can be observed by running experiments at $E_{\mathrm{d}}=0.150 \mathrm{~V}$ (Fig. $6 \mathrm{c}$ and d). The Ag dendritic growth initiates at tip sites of 3-D Ag crystals leading to acicular growth centres shooting at random, although the transition in the Ag growth mode appears outstandingly clear in the SEM micrographs of Ag electrodeposits produced potentiodynamically (Fig. 6g and $h$ ).

\section{DISCUSSION}

\subsection{General features}

The preceding data provide a reasonable framework for discussing the mechanism of $\mathrm{Ag}$ electrodeposition starting from the formation of the $\mathrm{Ag}$ monolayer for $E_{\mathrm{d}} \cong E_{\mathrm{rev}}$ to the development of branched dendrites as both the amount of $\mathbf{A g}$ becomes sufficiently large and $E_{\mathrm{d}} \leftarrow E_{\text {rev }}$.

The analysis of the electrochemical and SEM results indicates that both the $\mathbf{A g}$ electrodeposition overvoltage and the electrodeposition time play an important role in determining the $\mathrm{Ag}$ growth mode. It is therefore interesting to combine the global information related to the electrocrystallization of $\mathrm{Ag}$ for deriving a general mechanism for the process over a wide range of experimental conditions.

Kinetic changes along the different stages of the $\mathrm{Ag}$ electrodeposition process can be immediately derived throughout the voltammetric data and the potentiostatic current transients. The latter provides a deterministic picture of the $\mathrm{Ag}$ electrodeposition kinetics in terms of the formation of a new phase. Changes at the $\mathrm{Ag}$ growing surface can be distinguished from SEM micrographs, and they supply information about the restructuring of the $\mathrm{Ag}$ electrodeposits, including the development of electrodeposited $\mathbf{A g}$ fractal surfaces[18].

\subsection{Kinetic conclusions derived from voltammetry data}

At the early stages of $\mathrm{Ag}$ electrodeposition the relatively large value of the exchange current density for the $\mathrm{Ag} / \mathrm{Ag}^{+}$electrode reaction $\left(j_{0} \cong 1.0 \mathrm{~A} \mathrm{~cm}^{-2}\right)[19]$ favours the rapid build up of a hemispherical diffusion layer around the 3-D nuclei implying a radial concentration gradient of $\mathrm{Ag}^{+}$ions. When the number of growing 3-D crystals becomes sufficiently large, the overlapping of local diffusion layers gives rise to an integral diffusion layer of instantaneous thickness $\delta(t)$ around the spherical substrate. The value of $\delta(t)$ as well as the concentration profile can be estimated from the corresponding solution of Fick's equation[17]. At this stage as the average size of 3-D nuclei becomes sufficiently small compared with $\delta(t)$, the Ag layer grows entirely within the diffusion layer built up around the spherical substrate. This explains why the pseudo-limiting cathodic limiting currents read in the voltammograms run at different $v$ s coincide with the values calculated by taking $r_{0}=0.075 \mathrm{~cm}$, and $D_{\mathrm{Ag}}^{+}=4.0 \times$ $10^{-6} \mathrm{~cm}^{2} \mathrm{~s}^{-1}$. In this case the formation of relatively large and flat crystals with a hexagonal geometry (Fig. 6) takes place within the diffusion layer built up around the spherical electrode.

After a certain critical voltammetric Ag electrodeposition charge has been reached, the birth of dendrites begins at certain preferential sites located at corners and edges of large crystals (Fig. $6 \mathrm{~g}$ and $\mathrm{h}$ ). Then, in a relatively short time a number of dendrites emerge from the spherical diffusion layer region. The development of dendrites implies a fast local $\mathbf{A g}$ electrodeposition taking place for $E_{\mathrm{d}}<E_{\phi}$, and when a certain $\mathrm{Ag}$ electrodeposition charge density has been exceeded.

The preceding mechanism opens several possibilities for the control of the nucleation and growth of dendrites, namely an activation control by the proper $\mathrm{Ag}$ electrodeposition reaction (case 1), a diffusion control by $\mathrm{Ag}^{+}$ions to dendrite tips (case 2), and a resistance control due to the electric field built up during the $\mathrm{Ag}$ dendritic growth (case 3). Case 1 seems to be rather unlikely because of the high value of $j_{0}$ for the $\mathrm{Ag} / \mathrm{Ag}^{+}$electrode[19]. Case 2 depends on the reciprocal of the radius of curvature of the dendrite tip which is within 3-30 nm, as it was derived from SEM micrographs at $\times 50,000[18]$. This would imply limiting current density values ranging between 0.1 and $1.0 \mathrm{~A} \mathrm{~cm}-2$ exceeding the experimental values by $2-3$ orders of magnitude (Fig. 1b).

The high current densities expected at the tips of dendrites should produce an electric field at the solution side due to the migration of anions which cannot be completely screened by other ionic species. This electric field, which becomes proportional to both the applied potential and the concentration of the supporting electrolyte, tends to slow down the rate of the Ag electrodeposition process[20]; therefore the kinetics of the $\mathrm{Ag}$ dendritic growth should involve a combined contribution of migration and diffusion. 


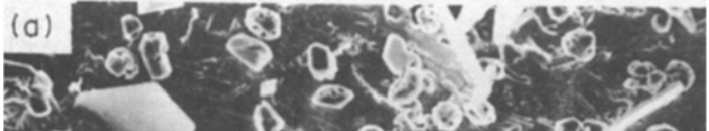

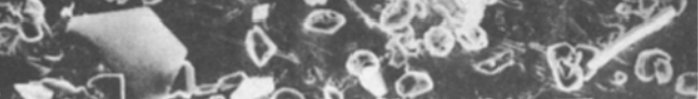

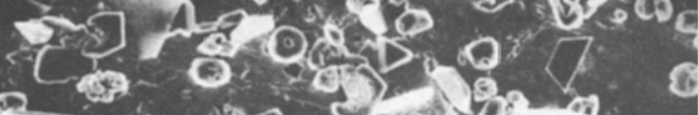

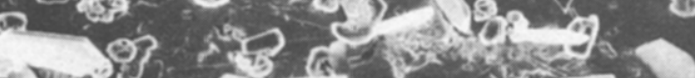
(4)

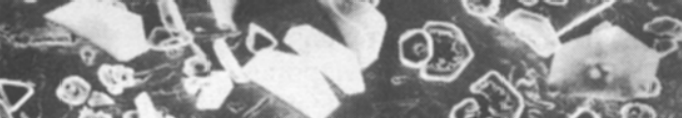

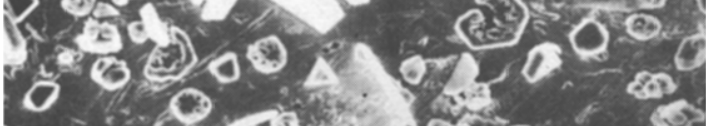

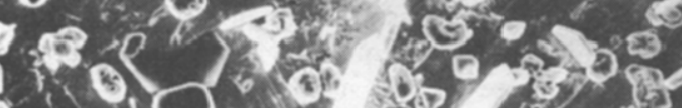
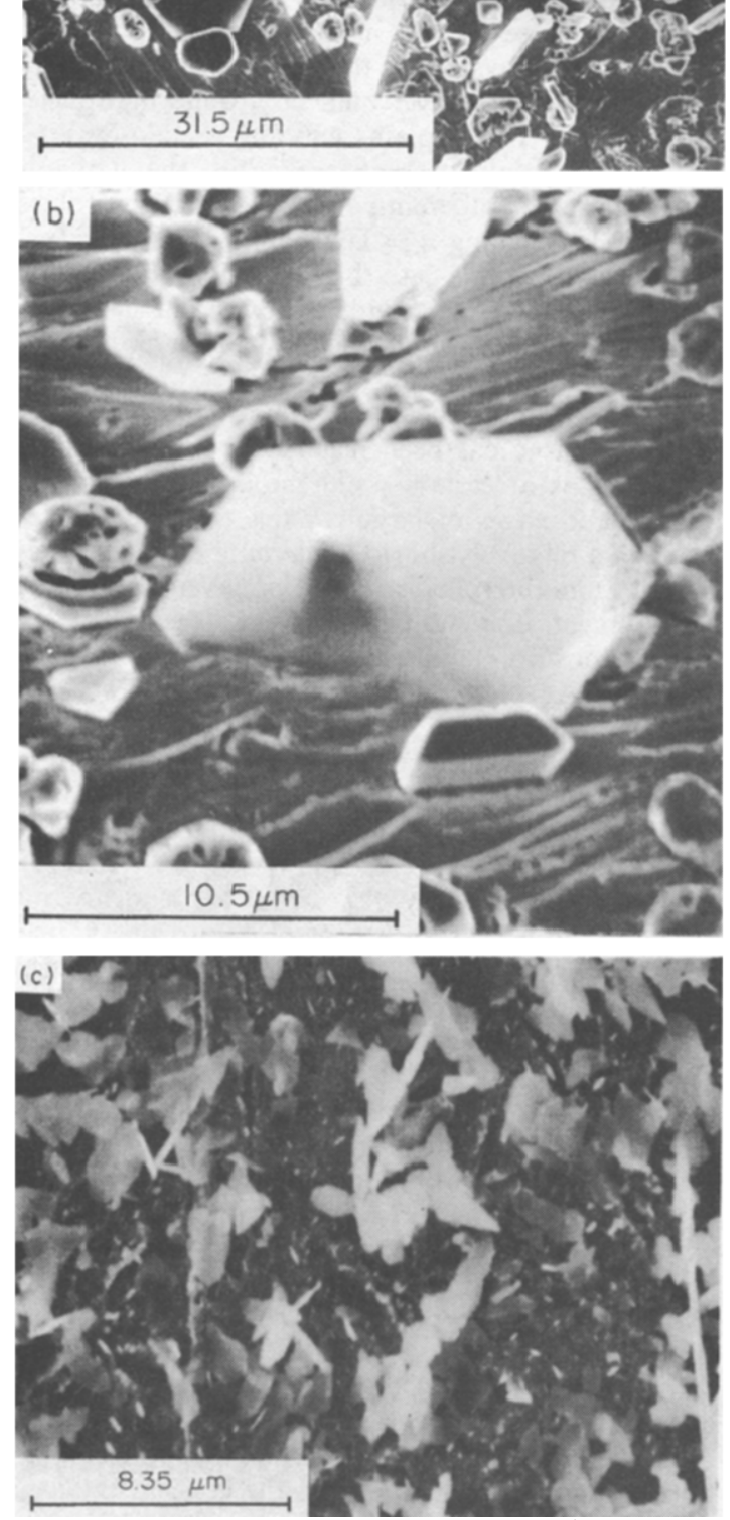
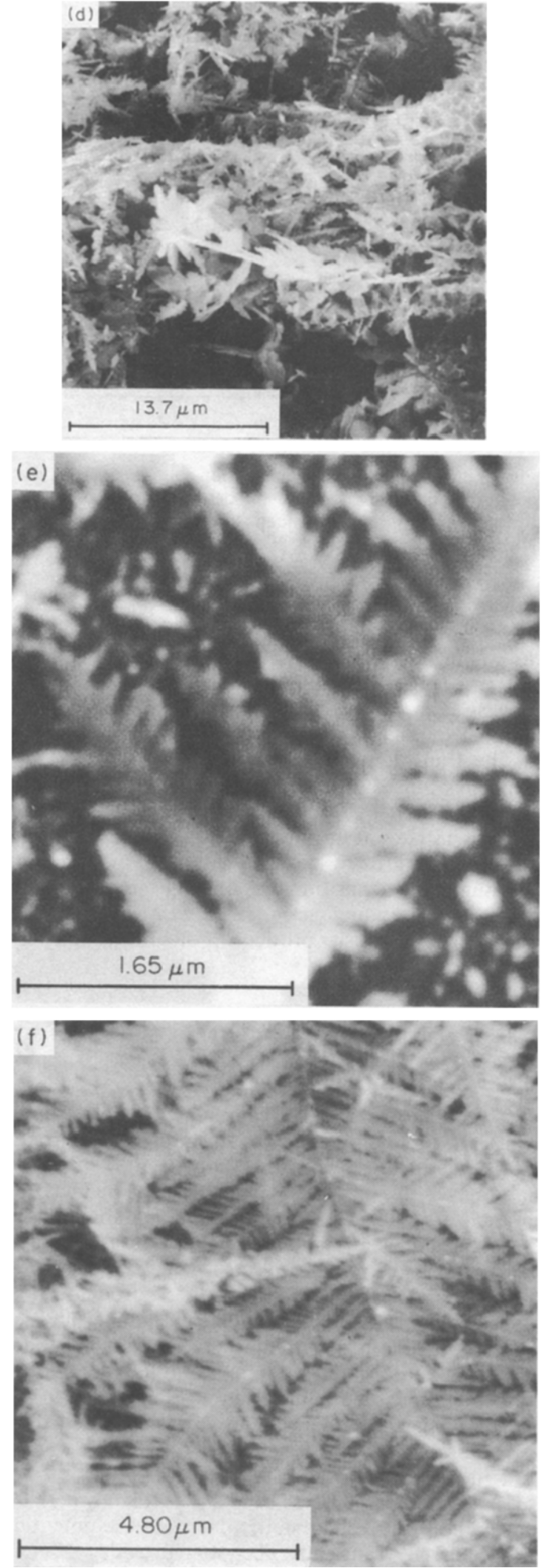

Fig. 6(a-f) 

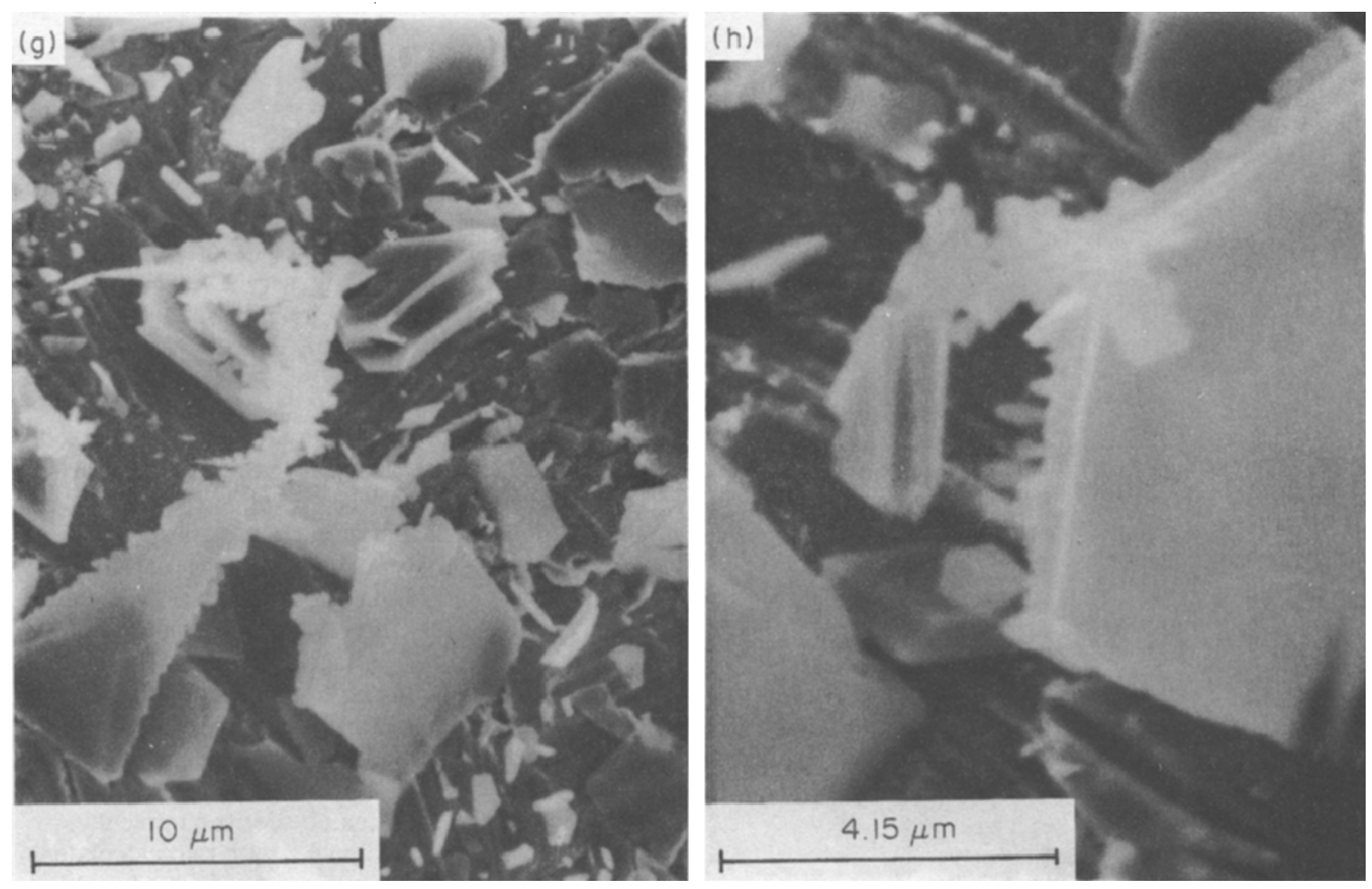

Fig. 6(g and $h)$

Fig. 6. SEM micrographs of different $\mathrm{Ag}$ electrodeposits from $0.5 \mathrm{M} \quad \mathrm{Na}_{2} \mathrm{SO}_{4}+10^{-2} \mathrm{M}$ $\mathrm{H}_{2} \mathrm{SO}_{4}+5 \times 10^{-3} \mathrm{M} \mathrm{Ag} \mathrm{SO}_{4}$. (a) and (b) $E_{\mathrm{d}}=0.320 \mathrm{~V}$; (c) and (d) $E_{\mathrm{d}}=0.150 \mathrm{~V}$; (e) and (f) $E_{\mathrm{d}}=-0.200 \mathrm{~V} ;(\mathrm{g})$ and $(\mathrm{h})$ the initiation of dendritic growth of $\mathrm{Ag}$ resulting from a linear potential sweep run at $0.001 \mathrm{~V} \mathrm{~s}^{-1}$ from $E_{\text {rev }}$ down to $E_{\mathrm{sc}}=0.075 \mathrm{~V}$.

This fact is also reflected in the change of the cathodic pseudo-limiting current with the supporting electrolyte concentration, as shown in Table 1 . These results are in qualitative agreement with the behaviour of ionic mass transfer processes in electrochemistry[21] where in the absence of supporting electrolyte the diffusion plus migration limiting current density attains values about twice that expected for pure diffusion. It should be noted that from the mathematical standpoint the diffusion field (Fick's equation) and the electric field (Laplace equation) established at the tips of dendrites are formally analogous. Furthermore, the growth of dendrites outside the diffusion layer around the $\mathrm{Pt}$ substrate implies the development of a $\mathrm{Ag}$ fractal surface with a dimension equal to 2.5[18], a figure which is consistent with a diffusion limiting aggregation (DLA) growth model for $\mathrm{Ag}$ dendrites under either a diffusion or an electric field control[22].

\subsection{Current transients modelling}

4.3.1. The 2-D and 3-D Ag layer growth mechanism. Considering that all the cathodic current transients were run on the Pt substrate previously held at $0.70 \mathrm{~V}$ for a few seconds, one can assure that the substrate was always free of $\mathrm{O}$ adatoms, and covered by a small fraction ( $c a 0.05 \mathrm{mC} \mathrm{cm}^{-2}$ ) of upd $\mathrm{Ag}$ monolayer [23].

The initial $(t<1 \mathrm{~s})$ current decrease can be related to the formation of a $2-\mathrm{D} \mathrm{Ag}$ layer by an adsorption-desorption process obeying a Langmuir type isotherm[12]. The adsorption-desorption mech anism combined with nucleation and 2-D growtl under diffusion control was proposed earlier to inter pret the kinetics of the $\mathrm{Ag}$ upd at $E_{\mathrm{d}} \cong E_{\text {rev }}[23]$. Fo: $E_{\mathrm{d}}<E_{\mathrm{rev}}$ one should expect that in the isotherm th $\mathrm{Ag}$ adsorption contribution predominates over th Ag desorption term, so that $j_{2-\mathrm{D}}$, the current densit: related to the formation of the 2-D Ag layer, can bi written as follows[12]:

$$
j_{2-\mathrm{D}}=P_{1} \exp \left(-P_{2} t\right),
$$

where $P_{1}=k_{\mathrm{a}} q_{\mathrm{M}}, P_{2}=k_{\mathrm{a}}+k_{\mathrm{d}}$, with $k_{\mathrm{a}} \gg k_{\mathrm{d}}$, and $P_{1}$ $P_{2}=q_{\mathrm{M}} . k_{\mathrm{a}}$ and $k_{\mathrm{d}}$ are the rate constants for th. adsorption and the desorption processes, respect ively, and $q_{\mathrm{M}}$ is the charge density involved in th. adsorption process.

On the other hand, at $E_{\mathrm{d}}<E_{\mathrm{rev}}$ the adsorption process is accompanied by two other processes namely a $2-\mathrm{D} \Rightarrow 3-\mathrm{D} \quad \mathrm{Ag}$ surface rearrange ment[24, 25], and a $\mathrm{Ag}$ nucleation and 3-D growt] under diffusion control. The latter can be associater with both the current increase and the current maxi mum seen in the current transients.

Let us now consider the current transients relate to the early stages of $\mathrm{Ag}$ 3-D growth. In this case, th corresponding current density, $j_{3-D}$, apparently obey a progressive nucleation and 3-D growth under diffu sion control, as already concluded from voltammetr 


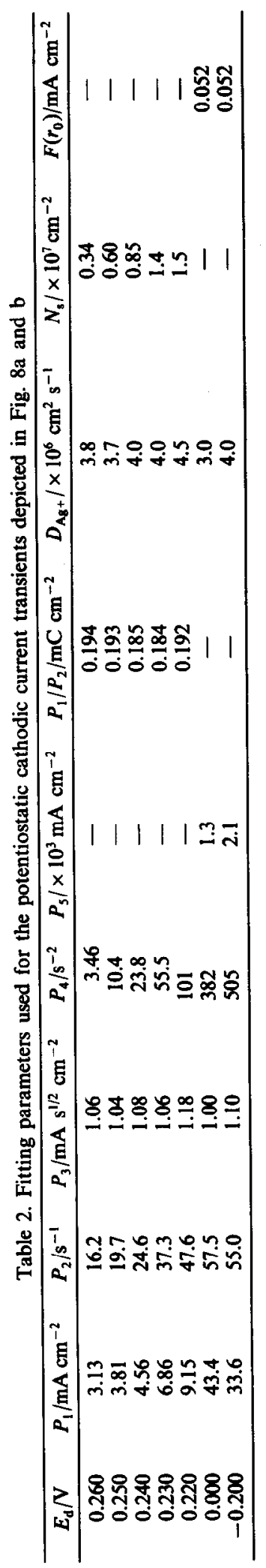

data. The corresponding apparent current density is given by[26]:

$$
j_{3-\mathrm{D}}=\left[P_{3} t^{-1 / 2}+F\left(r_{0}\right)\right]\left[1.0-\exp \left(-P_{4} t^{2}\right],\right.
$$

where $\quad P_{3}=z F D^{1 / 2} c / \pi^{1 / 2}, \quad F\left(r_{0}\right)=z F D c / r_{0}, \quad P_{4}=$ $\pi K D N_{0} A, K=4 / 3(8 \pi M c / \rho)^{1 / 2}, D$ and $c$ are the diffusion coefficient and the bulk concentration of $\mathrm{Ag}^{+}$ ion, respectively, and $N_{0} A$ is the nucleation rate. For $t \Rightarrow 0, P_{3} \Rightarrow F\left(r_{0}\right)$, and for $t \Rightarrow \infty$ equation (2) becomes $j_{3-\mathrm{D}} \Rightarrow F\left(r_{0}\right)$ as experimentally observed for $t>t_{\mathrm{M}}$ and $E_{\mathrm{d}}<0.30 \mathrm{~V}$ (Fig. 8). Thus, for $E_{\mathrm{rov}}<E_{\mathrm{d}}<E_{\phi}$ and $t<1.5 \mathrm{~s}, j_{t}$, the overall current density is:

$$
j_{t}=j_{2-\mathrm{D}}+j_{3-\mathrm{D}} \text {. }
$$

By using equation (3) and the parameters assembled in Table 2 the current transients can be satisfactorily reproduced (Fig. $7 \mathrm{a}$ and b). From the $\boldsymbol{P}_{1} / \boldsymbol{P}_{2}$ ratio $q_{\mathrm{M}}=0.19 \mathrm{mC} \mathrm{cm}^{-2}$ is obtained, a figure which is lower than $0.360 \mathrm{mC} \mathrm{cm}^{-2}$, the charge density assigned to a complete 2-D Ag layer on Pt[12]. This difference indicates that the 2-D Ag layer is not fully developed at the early stages of the Ag opd in agreement with previous voltammetric results showing in this case the simultaneous presence of 3-D A growing centres and $\mathrm{H}$ adatoms on bare $\mathrm{Pt}$ domains[25]. Otherwise, the value of $D_{A_{g}}^{+}=4.0 \times$ $10^{-6} \mathrm{~cm}^{2} \mathrm{~s}^{-1}$ for $\mathrm{Ag}^{+}$ions can be derived immediately from $P_{3}$, a figure which coincides with that calculated for the present system from data reported in the literature[27]. Furthermore, from $\boldsymbol{P}_{4}$ the potential dependence of the nucleation rate can also be obtained. Thus, from the $A N_{0} t_{M}$ product, $N_{3}$, the density of $\mathrm{Ag}$ nuclei is in the $10^{6}-10^{7} \mathrm{~cm}^{-2}$ range, in good agreement with figures derived from the SEM micrographs. The coincidence in the values of $N_{s}$ accomplished from two independent methods justifies the application of the preceding model to the present system, despite the criticisms which have been arisen on the grounds that no agreement could be found between the experimental $N_{3}$ value and that predicted by the model[28]. It should be noted that there are alternative models based on strong assumptions which can be also used to account for the shape of the potentiostatic current transients[29-31]. However, the model represented by equations (1)-(3) involves a set of adjusting parameters which have a reasonable physical meaning for $\mathrm{Ag}$ electrodeposition.

In conclusion, for upd $\mathrm{Ag}\left(E_{\mathrm{d}}>E_{\text {rev }}\right)$ and opd $\mathrm{Ag}$ $\left(E_{\mathrm{rev}}>E_{\mathrm{d}}>E_{\phi}\right)$, the kinetics of the early stages of $\mathrm{Ag}$ electrodeposition obeys principally an adsorption nucleation and 3-D growth mechanism controlled by the $\mathrm{Ag}^{+}$ion diffusion from the solution.

4.3.2. $\mathrm{Ag}$ dendritic growth. The growth of $\mathbf{A g}$ dendrites can be observed for $E_{\mathrm{d}}<E_{\phi}$ after a certain induction time, $t_{\mathrm{i}}$. In this case the current density initially decays as one would expect for a 3-D phase growth under diffusion control. Therefore, as a first approximation for a constant solution composition, equation (2) can be formally extended to the present situation, considering an additional $j$ vs $t$ term specifically related to the $\mathrm{Ag}$ dendritic growth, when the minimum current density observed in the potentiostatic current transients has been exceeded. Then the total current density as expressed by equation (3) becomes:

$$
j_{t}=j_{2-\mathrm{D}}+j_{3-\mathrm{D}}+j_{\mathrm{d}},
$$



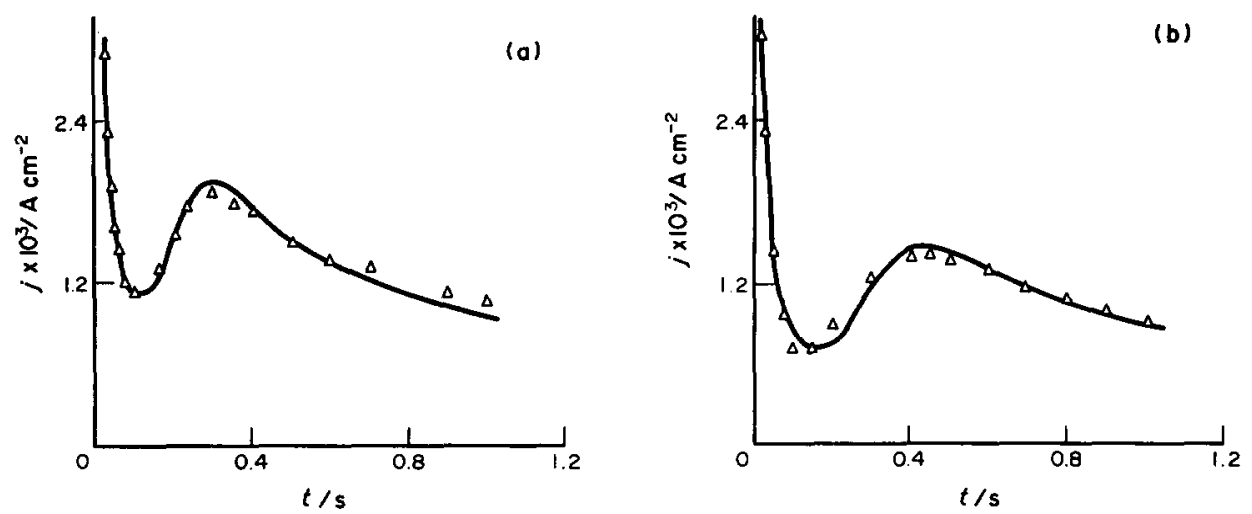

Fig. 7. Comparison of experimental (solid line) and calculated $(\triangle)$ potentiostatic current transients. $0.5 \mathrm{M}$ $\mathrm{Na}_{2} \mathrm{SO}_{4}+10^{-2} \mathrm{M} \mathrm{H}_{2} \mathrm{SO}_{4}+5 \times 10^{-3} \mathrm{M} \mathrm{Ag}_{2} \mathrm{SO}_{4}$. (a) $E_{\mathrm{d}}=0.240 \mathrm{~V}$. (b) $E_{\mathrm{d}}=0.250 \mathrm{~V}$. Fitting parameters are assembled in Table 2.

where $j_{2-\mathrm{D}}$ and $j_{3-\mathrm{D}}$ are given by equations (1) and (2), respectively, and $j_{\mathrm{d}}$ can be expressed by:

$$
j_{\mathrm{d}}=P_{5}\left(t-t_{\mathrm{i}}\right)
$$

Equation (5) can be related to a progressive nucleation and 1-D growth of $\mathrm{Ag}$ dendrites[29]. In this case, $P_{5}=z F k^{\prime} 2 \pi r^{2} N_{0}^{\prime} \alpha, k^{\prime}$ stands for the potentialdependent electrochemical rate constant, $N_{0}^{\prime} \alpha$ is the nucleation rate, and $2 \pi r^{2}$ is the constant capture area at dendrite tips. Accordingly, the following explicit general equation for the overall cathodic current
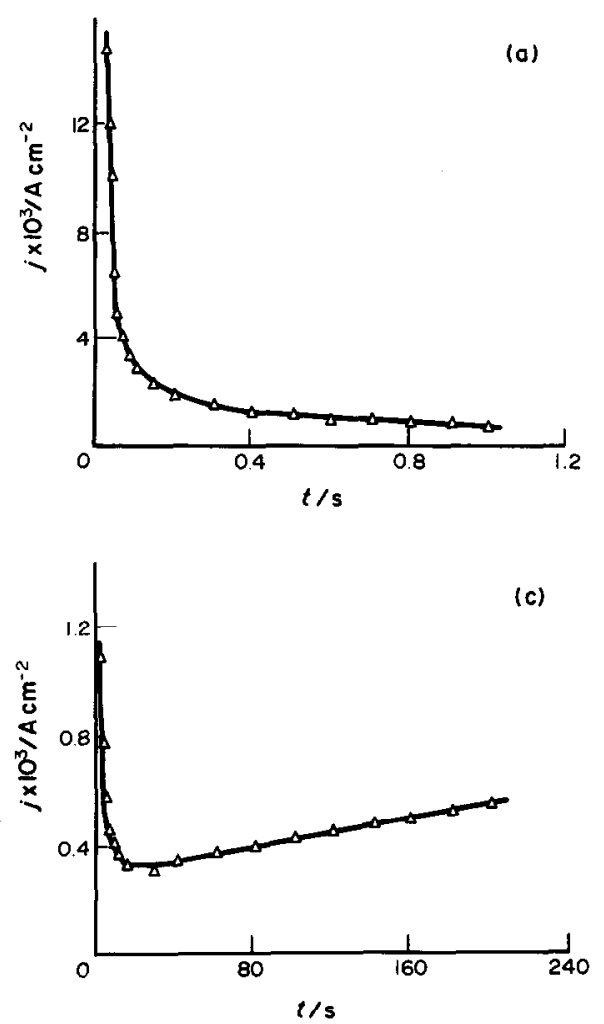

transients related to $\mathrm{Ag}$ electrodeposition can be written as:

$$
\begin{aligned}
j_{t}=P_{\mathrm{i}} & \exp \left(-P_{2} t\right)+\left[P_{3} t^{-1 / 2}+F\left(r_{0}\right)\right] \\
& \times\left[1-\exp \left(-P_{4} t^{2}\right)\right]+P_{5}\left(t-t_{\mathrm{j}}\right) .
\end{aligned}
$$

For $E<E_{\phi}$ limiting forms of equation (6) can be used. Thus, for $t<1 \mathrm{~s}, \quad F\left(r_{0}\right) \ll P_{3} t^{-1 / 2}$, $\exp \left(-P_{4} t^{2}\right) \Rightarrow 0$, and $P_{5}\left(t-t_{4}\right)=0$, equation (6) becomes:

$$
j_{\mathrm{t}}=P_{1} \exp \left(-P_{2} t\right)+P_{3} t^{-1 / 2}
$$
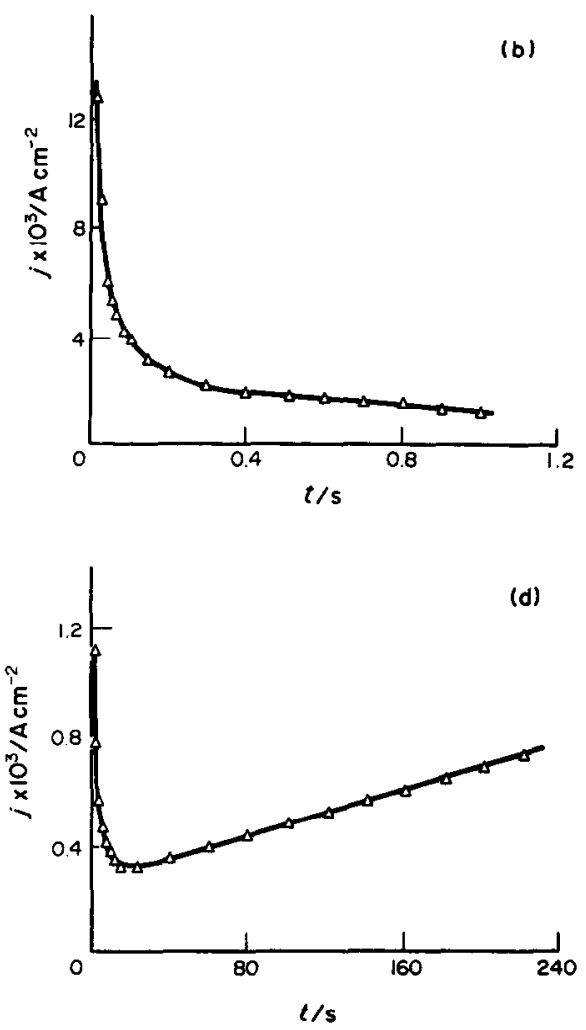

Fig. 8. Comparison of experimental (solid line) and calculated $(\triangle)$ potentiostatic current transients. $0.5 \mathrm{M}$ $\mathrm{Na}_{2} \mathrm{SO}_{4}+10^{-2} \mathrm{M} \mathrm{H}_{2} \mathrm{SO}_{4}+5 \times 10^{-3} \mathrm{M} \mathrm{Ag}_{2} \mathrm{SO}_{4}$. (a) $E_{\mathrm{d}}=0.00 \mathrm{~V}$; (b) $E_{\mathrm{d}}=-0.200 \mathrm{~V}$; (c) $E_{\mathrm{d}}=0.00 \mathrm{~V}$; (d) $E_{\mathrm{d}}=-0.200 \mathrm{~V}$. Fitting parameters are assembled in Table 2 . 
On the other hand, for $1 \mathrm{~s}<t<10 \mathrm{~s}$, both exponential terms in equation (6) tend to disappear, so that

$$
j_{\mathrm{t}}=P_{3} t^{-1 / 2}+F\left(r_{0}\right) \text {. }
$$

Finally, for $t>23 \mathrm{~s}$ equation (6) becomes:

$$
j_{t}=\left[P_{3} t^{-1 / 2}+F\left(r_{0}\right)\right]+P_{5}\left(t-t_{\mathrm{i}}\right)=P_{3}^{\prime}+P_{5}\left(t-t_{\mathrm{i}}\right) \text {, }
$$

where $t$ is given in seconds, $t_{\mathrm{i}}=23 \mathrm{~s}$ and $P_{3}^{\prime}=$ $0.314 \mathrm{~mA} \mathrm{~cm}^{-2}$.

The current transients recorded for $E<E_{\phi}$ can be reproduced by using equation (6) with the set of parameters assembled in Table 2 (Fig. 8a-d). One can observe that the value of $P_{3}^{\prime}$ coincides with the cathodic pseudo-limiting current density in the voltammograms (Fig. 1a). However, both figures exceed by a factor of about six the value expected exclusively from $F\left(r_{0}\right)$. Correspondingly, the apparent thickness of the diffusion layer around the sphere related to the growth of $\mathbf{A g}$ dendrites as calculated from $P_{3}^{\prime}$, is about six times smaller than that expected from $F\left(r_{0}\right)$. These differences suggest that the penetration of dendrites through the spherical diffusion field around the Pt substrate occurs before the full development of the diffusion layer as determined by $F\left(r_{0}\right)$ takes place. It should be noted that in the estimation of the apparent thickness of the diffusion layer through $F\left(r_{0}\right)$ the increase in the diameter of the sphere due to the small amount of $\mathrm{Ag}$ electrodeposited up to $E_{\phi}$ has been neglected[18].

On the other hand, $P_{5}$ increases as $E_{d}$ is shifted negatively and the supporting electrolyte concentration increases (Figs 5 and $8 c-d$ ) as one would expect for a process predominantly controlled at this stage by electric field effects, ie the $\mathrm{Ag}$ dendritic growth mode should imply a significant migration contribution. In agreement with this conclusion, very recent optical results[35] demonstrate that the rate of $\mathrm{Ag}$ dendritic growth is very close to the rate of migration of sulphate ions in solution under a $1 \mathrm{~V} \mathrm{~s}^{-1}$ electric field.

\subsection{Other kinetics aspects of $\mathrm{Ag}$ electrodeposition derived from the SEM micrographs}

Additional features of the Ag electrodeposition process taking place within the initial diffusion layer, particularly the formation of flat large crystals approaching a hexagonal geometry, can be understood from the inspection of SEM micrographs. Firstly, the probable mechanism of the formation of those Ag crystals, and secondly, the triggering of the Ag dendritic growth at corners and edges of large crystals, should be considered.

The SEM micrographs (Fig. 6) show that large crystals exhibiting a quasi-2-D growth pattern are located within the spherical diffusion layer standing up with an edge contacting the substrate. The formation of these structures can be tentatively explained in terms of the impinging of $\mathrm{Ag}^{+}$ions at the upper edges where the diffusion resistance becomes smaller, and a recrystallization at borders of large crystals which occurs at the expense of small 3-D crystals surrounding them. This type of recrystallization was reported a long time ago[32].
The SEM microgtaphs also show that Ag dendrites start to grow at large curvature sites of corners and edges of relatively large crystals offering a minimum diffusion resistance for $\mathrm{Ag}^{+}$ion. Under these circumstances local fluctuations induce randomly oriented precursor nuclei for dendrite growth. The competition among these nuclei (shadowing effect) leads to the development of a single dendrite which rapidly moves out of the diffusion layer and becomes a branched Ag dendritic growth as already discussed in Sections 4.2 and 4.3 .

\subsection{A comprehensive approach to $\mathrm{Ag}$ electrode- position starting on a foreign substrate}

When the present results are combined with those reported earlier for the electrodeposition of $\mathrm{Ag}$ on $\mathrm{Pt}$ under upd $[12,14,23,25,33]$ and opd $[8,18,19,26,34]$ conditions, the following comprehensive picture of the entire process can be presented.

(i) At $E_{\mathrm{d}}>E_{\mathrm{rev}}$ the first Ag layer electrodeposition on a free Pt surface obeys an adsorption-desorption mechanism.

(ii) At $E_{\mathrm{d}} \cong E_{\mathrm{rev}}$, the electrodeposition of a second Ag layer takes place obeying an adsorptiondesorption combined with a nucleation and 2-D growth process under diffusion control.

(iii) At $E_{\mathrm{d}}<E_{\mathrm{rev}}$, the formation of a complete 2-D Ag layer is impeded because of the 2-D $\Rightarrow 3-\mathrm{D} A g$ surface rearrangement described elsewhere[25], which leads to the simultaneous appearance of free $\mathrm{Pt}$ areas and 3-D Ag nuclei. The formation of the Ag 2-D layer proceeds through an adsorption mechanism, whereas the formation of the 3-D Ag layer fits a progressive nucleation and 3-D growth mechanism under diffusion control of $\mathrm{Ag}^{+}$ions.

(iv) At $E_{\mathrm{d}}<E_{\phi}, \mathrm{Ag}$ dendritic growth appears after a certain induction period, following progressive nucleation and 1-D growth. This process is triggered at edges and corners of large $\mathrm{Ag}$ crystals where a minimum diffusion resistance for $\mathrm{Ag}$ ions is accomplished. Dendritic growth takes place outside the diffusion layer of the spherical substrate under an electric field control, leading to the development of a Ag fractal surface[18].

Acknowledgements-Financial support for this work form the Gobierno de Canarias (Dirección General de Universidades e Investigación) under Contract $\mathrm{Nr}$. $46 / 01.06 .88$ is gratefully acknowledged.

\section{REFERENCES}

1. E. B. Budevski, in Comprehensive Treatise of Electrochemistry (Edited by B. E. Conway, J. O'M. Bockris, E. Yeager, S. U. M. Khan and R. E. White), Vol. 7, p. 399. Plenum Press, New York (1983); A. R. Despic, ibid., Vol. 7, p. 451.

2. D. M. Kolb, in Advances in Electrochemistry and Electrochemical Engineering (Edited by H. Gerischer and C. W. Tobias), Vol. 11. Wiley, New York (1978).

3. W. J. Lorenz, H. D. Herrmann, N. W. Wuthrich and F. Hilbert, J. electrochem. Soc. 121, 1167 (1974).

4. B. I. Podlovchenko and E. A. Kolyadko, J. electroanal. Chem. 234, 225 (1987). 
5. E. Budevski, V. Bostanov, T. Vitanov, Z. Stoynov, A. Kotzeva and R. Kaischev, Electrochim. Acta 11, 1697 (1966).

6. G. Staikov, W. Obretenov, V. Bostanov, E. Budesvski and H. Bort, Electrochim. Acta 25, 1619 (1980).

7. J. A. Harrison and H. R. Thirsk, in Electroanalytical Chemistry (Edited by A. J. Bard), Vol. 5, p. 67. Marcel Dekker, New York (1966).

8. A. R. Despic and K. I. Popov, in Modern Aspects of Electrochemistry (Edited by B. E. Conway and J. O'M. Bockris), Vol. 7, p. 199. Butterworth, London (1973).

9. A. C. Chialvo, W. E. Triaca and A. J. Arvia, J. electroanal. Chem. 146, 93 (1983).

10. A. Visitin, W. E. Triaca and A. J. Arvia, J. electroanal. Chem. 284, 465 (1990)

11. K. I. Popov and M. D. Maximovic, in Modern Aspects of Electrochemistry (Edited by B. E. Conway, J. O'M. Bockris and R. E. White), Vol. 19, p. 193. Plenum Press, New York (1989).

12. R. C. Salvarezza, D. V. Vásquez Moll, M. C. Giordano and A. J. Arvia, J. electroanal. Chem. 213, 301 (1986).

13. A. Milchev, T. Chierchie, K. Juttner and W. J. Lorenz, Electrochim. Acta 32, 1039 (1987); 32, 1043 (1987).

14. F. El Omar, R. Durand and R. Faure, J. electraanal. Chem. 160, 385 (1984).

15. D. Aberdam, C. Salem, R. Durand and R. Faure, Surf. Sci. 239, 71 (1990).

16. G. L. M. K. S. Kahanda and M. Tomkiewicz, J. electrochem. Soc. 137, 3423 (1990).

17. P. Delahay, New Instrumental Methods in Electrochemistry. Interscience, New York (1954)

18. A. Hernández Creus, P. Carro, S. González, R. C. Salvarezza and A. J. Arvia, J. electrochem. Soc. 139, 1064 (1992).
19. G. Hills, A. K. Pour and B. Scharifker, Electrochim Acta 28, 891 (1983).

20. V. Fleury, J. N. Chazalviel, M. Rosso and B. Sapoval, J. electroanal. Chem. 290, 249 (1990).

21. J. Newman, Electrochemical Systems, Ch. 19, p. 353. Prentice-Hall, London (1973).

22. P. Meakin, in The Fractal Approach to Heterogeneous Chemistry (Edited by D. Avnir), p. 131. Wiley, New York (1989).

23. B. S. Parajón Costa, C. Canullo, D. Vásquez Moll, R. C. Salvarezza, M. C. Giordano and A. J. Arvia, J. electroanal. Chem. 244, 261 (1988).

24. D. Margheritis, R. C. Salvarezza, M. C. Giordano and A. J. Arvia, J. electroanal. Chem. 229, 327 (1987).

25. D. C. Alonzo and B. R. Scharifker, J. electroanal. Chem. 274, 167 (1989).

26. B. R. Scharifker and G. Hills, Electrochim. Acta 28, 879 (1983).

27. R. A. Robinson and R. H. Stokes, Electrolyte Solutions, p. 513. Butterworth, London (1959).

29. E. Bosco and S. K. Rangarajan, J. electroanal. Chem. 134, 213 (1982); 134, 225 (1982).

30. M. Sluyters-Rehbach, J. H. O. J. Wijenberg, E. Bosco and J. H. Sluyters, J. electroanal. Chem. 236, 1 (1987).

31. M. V. Mirkin and A. P. Nilov, J. electroanal. Chem. 283, 35 (1990)

32. A. E. Alexander and P. Johnson, Colloid Science, Vol. II, Ch. 20, p. 556. Oxford University Press, Oxford (1949).

33. T. Chierchie, C. Mayer, K. Juttner and W. J. Lorenz, J. electroanal. Chem. 191, 401 (1985).

34. T. Chierchie and A. Milchev, Electrochim. Acta 35, 1873 (1990).

35. A. Hernández Creus, A. Bolzan, P. Carro, S. González, R. C. Salvarezza and A. J. Arvia, J. electroanal. Chem. in press. 